\title{
Mss4 protein is a regulator of stress response and apoptosis
}

\author{
BM Walter ${ }^{1}$, C Nordhoff', G Varga ${ }^{2}$, G Goncharenko ${ }^{3}$, SW Schneider ${ }^{4}$, S Ludwig ${ }^{1}$ and V Wixler ${ }^{* 1}$
}

Mss4 (mammalian suppressor of Sec4) is an evolutionarily highly conserved protein and shows high sequence and structural similarity to nucleotide exchange factors. Although Mss4 tightly binds a series of exocytic Rab GTPases, it exercises only a low catalytic activity. Therefore Mss4 was proposed to work rather as a chaperone, protecting nucleotide free Rabs from degradation than as a nucleotide exchange factor. Here we provide further evidence for chaperone-like properties of Mss4. We show that expression levels of cellular Mss4 mRNA and protein are rapidly changed in response to a broad range of extracellular stress stimuli. The alterations are regulated mostly via the (c-jun $\mathrm{NH}_{2}$-terminal kinase) JNK stress MAPK signaling pathway and the mode of regulation resembles that of heat shock proteins. Similar to heat shock proteins, upregulation of Mss4 after stress stimulation functions protectively against the programmed cell death. Molecular analysis of the Mss4-mediated inhibition of apoptosis showed that interaction of Mss 4 with elF3f (eukaryotic translation initiation factor 3 subunit f), a member of the translation initiation complex and a protein with distinct pro-apoptotic properties, is the critical event in the anti-apoptotic action of Mss4.

Cell Death and Disease (2012) 3, e297; doi:10.1038/cddis.2012.37; published online 12 April 2012

Subject Category: Experimental Medicine

Apoptosis is an extraordinarily regulated, energy-dependent cellular process that leads to programmed cell death. It can be triggered by internal or external stimuli like oxidative stress, heat shock, inflammation or osmotic stress. Many cellular proteins are involved in advanced or retreated regulation of apoptosis. On response to cellular stress, a series of coordinated signaling as well as transcriptional and translational events are activated, leading to temporary rise of the cellular tolerance to stress by gathering of protective proteins. These chaperones preclude protein misfolding and aggregation $^{1}$ and function this way until stress reached a certain threshold. ${ }^{2}$ The best studied proteins with these properties are proteins of the heat shock protein family. ${ }^{3}$

Mss4 (mammalian suppressor of Sec4) is an evolutionarily highly conserved protein, which is expressed in all mammalian tissues. ${ }^{4}$ It has been shown that Mss4 interacts with exocytic Rab GTPases and with the conserved KXGFFKR intracellular domain of integrin $\alpha$-subunits. ${ }^{4-6}$ Although it was first proposed to function as a guanine nucleotide exchange factor (GEF) for Rab GTPases, ${ }^{7}$ it was soon described as a quite inefficient GEF and was thus suggested to function rather as a chaperone for exocytic Rab GTPases than as a GEF. ${ }^{6,8,9}$ On the other hand its interaction with integrins was shown to be important for coordinated activation of MMP-2 and -9 and remodeling of extracellular matrix proteins. ${ }^{10}$ In contrast to the scant functional data about Mss4, its structure has been solved by both NMR and crystallographic methods. ${ }^{8,11,12}$ The fold of Mss 4 is a central $\beta$-sheet, flanked by a $\beta$-hairpin and a small variable sheet. The four conserved regions, CR1-CR4, build a primary hydrophobic core with a $\mathrm{Zn}^{2+}$-binding site and encode a structural subdomain responsible for interaction with Rab GTPases. Structurally, Mss4 shows a striking similarity with the translationally controlled tumor-associated proteins. ${ }^{13}$ which are assumed to function as cellular chaperones protecting cells from heat shock $^{14}$ and regulating cell growth and acute allergic response. $^{15}$

The 47-kDa elF3f (eukaryotic translation initiation factor 3 subunit f) protein has been found to have distinct proapoptotic features. Originally it was described as part of the multi-subunit elF3 translation initiation factor that promotes the binding of eIF2, GTP and Met-tRNA to the 40S ribosome subunit to form the $43 S$ translation preinitiation complex. ${ }^{16}$ elF3 is built from 13 non-identical subunits. The active core consists of five subunits (elF3a, -b, -c, -g, -i) leaving the other eight to be modulators of the elF3 activity. ${ }^{17}$ Recent studies have shown that elF3f might not be necessary for global translation initiation, but rather inhibits translation. ${ }^{18,19}$ It harbors a MPN (Mpr1, Pad1 N-terminal) domain, which is characteristic for proteins of the Mov34 family. These proteins are involved in the modulation of the proteasome, translation initiation, pre-mRNA splicing and transcription. ${ }^{20}$ Other studies discovered that elF3f is downregulated in many tumors, and it has been shown that its overexpression leads

${ }^{1}$ Institute of Molecular Virology (IMV), Centre of Molecular Biology of Inflammation (ZMBE), Muenster University Hospital, Von-Esmarch-Str. 56, D-48149 Muenster, Germany; ${ }^{2}$ Institute of Immunology, Muenster University Hospital, Muenster, Germany; ${ }^{3}$ Department of Genetics, F. Scorina Gomel State University, Gomel, Belarus and ${ }^{4}$ Department of Dermatology, Medical Faculty Mannheim, Heidelberg University, Mannheim, Germany

${ }^{*}$ Corresponding author: V Wixler, Institute of Molecular Virology, Muenster University Hospital Medical School, Von-Esmarch-Str. 56, D-48149 Muenster, Germany. Tel: + 49251835 2216; Fax: + 49251855 7793; E-mail: vwixler@uni-muenster.de

Keywords: hydrogen peroxidase stress; Rabif; elF3; programmed cell death; AP-1; HSF1

Abbreviations: Mss4, mammalian suppressor of Sec4; elF3f, eukaryotic translation initiation factor 3 subunit f; HSF1, heat shock factor 1

Received 27.12.11; revised 07.03.12; accepted 07.03.12; Edited by RA Knight 
to decreased proliferation and increased apoptosis of tumor cells. ${ }^{21-23}$ This pro-apoptotic property was associated with the interaction of elF3f with CDK11p46 (cyclin-dependent kinase 11). This protein is a cleavage product of CDK11p110, which in turn is a target protein for caspase- 3 and therefore seems to be an important downstream effector of the apoptotic signaling. $^{24}$

Here we provide new data suggesting that Mss4 behaves similar to a heat shock protein in response to extracellular stress and that Mss4 inhibits stress-mediated apoptosis via direct interaction with elF3f.

\section{Results}

Regulation of Mss4 promoter activity. To understand how the expression of the Mss4 gene (accession no. NP_002862.2) is regulated, we performed a general examination of the complete $3.6-\mathrm{kb}$-long potential promoter region located between the KIh12 gene sequence and the translational atg start codon of Mss4 using the transcription element search software (TESS, Baxevanis, Wiley, Weinheim, Germany). The search revealed 47 potential TGAG/CTCA binding sites for
AP-1 (activator protein-1) and 34 NGAAN sites for HSF1 (heat shock factor 1) transcription factors (Figure 1a). To explore whether these sites also have a functional role in the transcriptional regulation of Mss4, the promoter sequence of Mss4 was cloned in front of a luciferase gene and transfected into human melanoma $A 7$ cells. In agreement with the promoter screening data, cotransfection of the reporter gene with plasmids coding for $c$-jun, $c$-fos, the wellknown components of AP-1 transcription factor ${ }^{25}$ or HSF1 but not Elk1, a transcription factor of the ETS family ${ }^{26}$ greatly changed the transcription of the reporter gene (Figure 1b). Of note, expression of both AP-1 and HSF1 transcription factors significantly repressed Mss4 promoter activity. An effective inhibition of the reporter gene was also observed when a 1-kb-long promoter region containing only 8 and 10 sites for AP-1 and HSF1 transcription factors, respectively, was used (data not shown).

Both HSF1 and AP-1 are transcription factors that are activated by stress factors. To study whether Mss4 promoter activity is generally downregulated by stress stimuli, HeLa cells were transfected with the luciferase reporter gene construct for $40 \mathrm{~h}$ and stimulated afterward for additional $5 \mathrm{~h}$
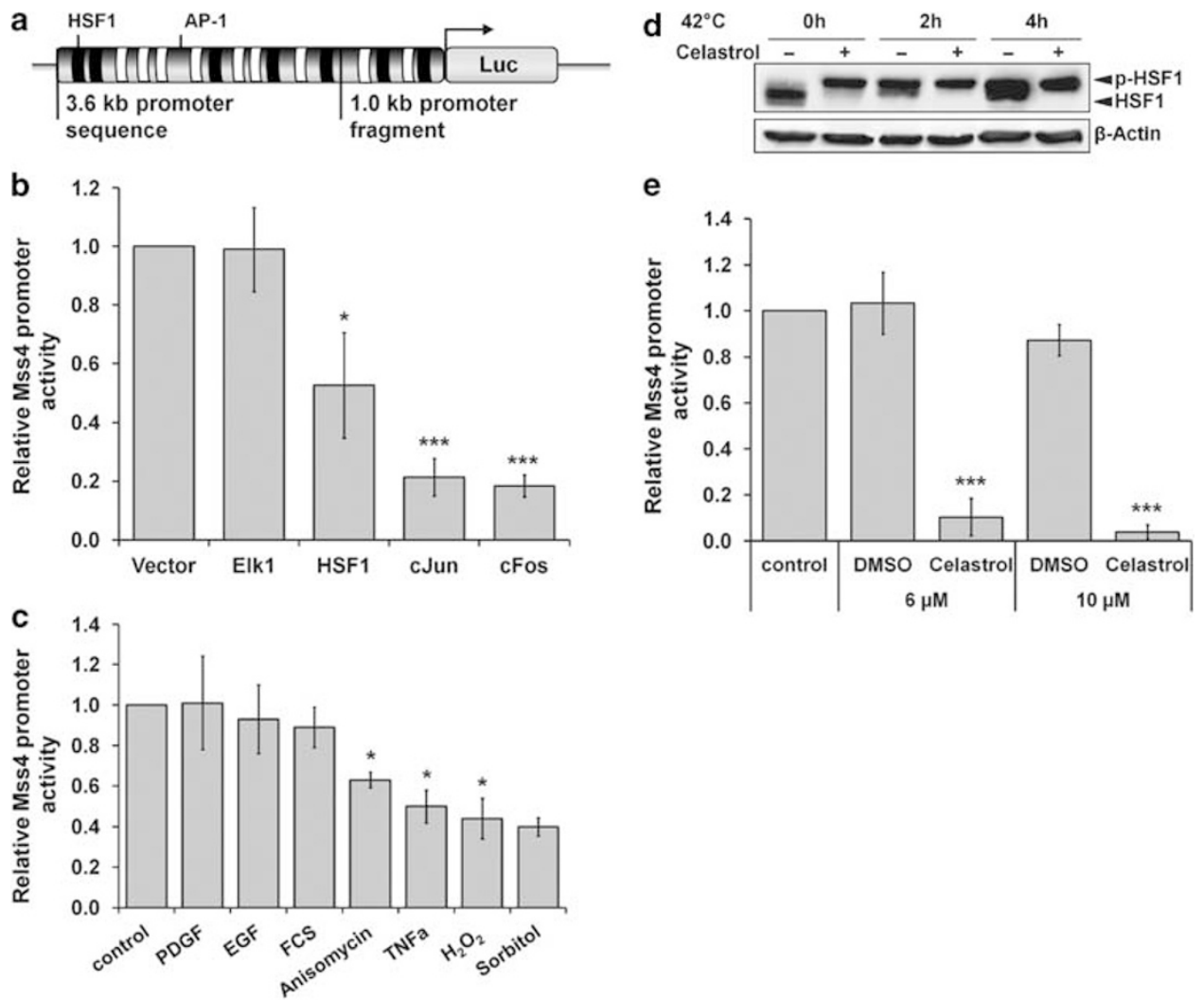

Figure 1 Regulation of the Mss4 promoter activity by HSF1 and AP-1. (a) Luciferase reporter gene construct with Mss4 promoter. The 47 and 34 potential binding sites for AP-1 and HSF1 transcription factors, respectively, present in the 3.6-kB long promoter sequence are shown schematically. The $1.0 \mathrm{~kb}$ fragment contains only 10 binding sites for AP-1 and 8 for HSF1. (b) A7 melanoma cells were transiently transfected with reporter construct driven by the 3.6-kb Mss4 promoter fragment along with indicated transcription factors and $48 \mathrm{~h}$ later the reporter gene activity was determined. (c) HeLa cells were transfected with reporter construct shown in A for $24 \mathrm{~h}$, starved overnight and stimulated for $5 \mathrm{~h}$ with indicated growth factors, chemical compounds or cytokines. (d) HeLa cells were treated with $10 \mu \mathrm{M}$ celastrol and additionally incubated at $42{ }^{\circ} \mathrm{C}$ for up to 4h. Western blot analysis shows expression and phosphorylation of HSF1. $\beta$-actin immunoblot served as loading control. (e) HeLa cells transfected for $40 \mathrm{~h}$ with reporter construct shown in A were stimulated with 6 or $10 \mu \mathrm{M}$ celastrol or DMSO as control for additional $5 \mathrm{~h}$ before the reporter gene activity was determined. Relative luciferase activity measured in unstimulated or vector transfected cells was taken as unity. Mean values \pm S.D. from at least three repeated experiments are shown. ${ }^{*} P<0.05$ and ${ }^{* * \star} P<0.001$ relative to vector-transfected or unstimulated control cells, $t$-test 
with different stress-inducing components or cytokines and growth factors. Indeed, the Mss4 promoter activity was significantly reduced after application of all stress stimuli used but not by growth stimulating factors (Figure 1c). The effect was independent of cell type used, as human HEK293 and A7, epithelial or melanoma cells, respectively, as well as mouse adenocarcinoma TS/A cells showed similar results (Supplementary Figure 1).

As a heat shock factor, HSF1 is rapidly phosphorylated and activated by temperature stress ${ }^{27,28}$ and temperature increase is probably the easiest way to study the role of endogenous HSF1. This, however, results in inactivation of the luciferase reporter enzyme. Therefore we incubated HeLa cells with celastrol, a known activator of HSF1 and a potent antioxidant. ${ }^{29}$ Indeed, celastrol stimulation was even more efficient in phosphorylation of endogenous HSF1 protein than incubation of cells at $42^{\circ} \mathrm{C}$ alone (Figure 1d). Accordingly, incubation of HeLa cells with either 6 or $10 \mu \mathrm{M}$ of celastrol significantly affected the activity of the luciferase reporter gene (Figure 1e). Interestingly, similar to AP-1 and in agreement with overexpression of HSF1, activation of the endogenous transcription factor also repressed the Mss4 promoter activity. Thus, the gained information of the promoter studies indicates a context between stress and heat stimulation and the regulation of Mss4.

Expression of endogenous Mss4 mRNA and protein changes in response to stress stimuli. To analyze the impact of heat on the mRNA and protein expression of Mss4, HeLa cells were incubated at $42^{\circ} \mathrm{C}$ for increasing time periods. The mRNA levels were analyzed by qRT-PCR and protein expression by western blotting. As expected, the increased temperature decreased the cell viability significantly, with almost a linear decline of cell number with the time (Figure 2a). The amounts of Mss4 mRNA (Figure 2b) and protein (Figure $2 \mathrm{c}$ ) in still alive cells, however, raised up at early stages of heat stress but declined with prolonged heat stimulation, a kinetic that is very typical for heat shock proteins. ${ }^{30,31}$ Although the maximum of mRNA expression was achieved at $4 \mathrm{~h}$ of heat shock application, the highest protein expression was measured $4 \mathrm{~h}$ later or $8 \mathrm{~h}$ after heat shock initiation.

In addition to the increase of protein expression after temperature rise, heat shock proteins also stabilize their mRNA. $^{31}$ The half-life time of heat shock protein mRNA is usually significantly increased in stressed cells, which ensures an amplified protein amount in cells in order to protect cellular proteins from misfolding and aggregation. Thus, we were wondering whether Mss4 did show similar properties after heat shock application. To analyze the mRNA half-life of Mss4, the cells were stressed for $2 \mathrm{~h}$ with $43^{\circ} \mathrm{C}$ and the transcription of cells was inhibited by actinomycin $D$ for additional time, up to $24 \mathrm{~h}$, at $37^{\circ} \mathrm{C}$. The amount of Mss 4 mRNA in actinomycin $D$ treated cells after different recovery times was compared with non-heat-stressed control cells (Figure 2d). This analysis showed that similar to heat shock proteins, the stability of Mss 4 mRNA was also increased by the short heat shock. Although the half-life of Mss4 mRNA in untreated cells was about $6.5 \mathrm{~h}$, it rose to $\sim 13 \mathrm{~h}$ in temperature challenged cells.
To judge the acquired results against other stress stimulation and to further analyze the role of the AP-1-induced repression of Mss4, we applied HeLa cells to hydrogen peroxide instead of heat shock. Hydrogen peroxide is a strong inducer of the cellular stress response and was one of the most prominent inhibitors of Mss4 promoter activity in our screen (Figure 1c). Similar to heat stimulation, application of hydrogen peroxide resulted in a strong decrease in HeLa cell number (Figure 2e). Also expression kinetics of Mss4 mRNA and protein were much alike the temperature challenge curves. The mRNA levels of Mss4 increased right after the beginning of the hydrogen peroxide stimulation, peaked after $8 \mathrm{~h}$ and decreased back to the basal level afterwards (Figure 2f). The increase in Mss4 protein expression was, similar to heat shock treatment, also delayed compared with mRNA and peaked later (Figure $2 \mathrm{~g}$ ). Similarly, the Mss4 mRNA half-time increased after hydrogen peroxide application from $\sim 6.5 \mathrm{~h}$ to $15 \mathrm{~h}$ (Figure $2 \mathrm{~h}$ ).

JNK and p38 stress MAPK pathways regulate Mss4 expression. Both HSF1 and AP-1 transcription factors are downstream targets of JNK and p38 MAPK stress signaling cascades and both heat shock and stress stimuli, like hydrogen peroxide are strong activators of the JNK- and p38- cascades. $^{32,33}$ Therefore, we next studied whether changes in activation of the two stress MAPK pathways would influence transcriptional activity of the Mss4 gene. The luciferase reporter gene containing the Mss4 promoter was transfected into A7 melanoma cells along with constructs representing either dominant negative (d.n.) or constitutively active (c.a.) forms of different members of MAPK signaling cascades and the luciferase activity measured $48 \mathrm{~h}$ later distinguished the Mss4 promoter activity. Data presented in Figure 3 clearly show that activation of both p38 and JNK pathway achieved by expression of c.a. mutants of the pathway members led to a significant reduction in Mss4 promoter activity. Further, inhibition of the JNK (Figure 3b) but not of the p38 (Figure 3a) pathway by d.n. mutants was additionally able to provoke the opposite effect, to enhance the Mss4 promoter activity. In good agreement with these data, inhibition of p38 or JNK kinases with SB203580 or SP600125 chemical compounds (Supplementary Figure 2) abrogated the inhibitory effect of constitutive active MKK6 or MKK7 (Figures 3c and d). Therefore it can be concluded, that the transcriptional expression of Mss4 is primarily regulated by MAPK stress signaling cascades.

Taken together, our results show that expression of Mss4 is regulated by stress stimuli and that changes in its expression resemble that of heat shock proteins. Shortly after stress application its mRNA is stabilized resulting in increased protein expression, but ongoing stress stimulation leads to downregulation of both mRNA and protein levels. Together, these data imply a possible role of Mss4 protein in protection of cells from stress stimuli.

Mss4 downregulation induces cell apoptosis. Ongoing presence of stress often ends in programmed cell death. To investigate whether Mss4 is involved in regulation of this process, we either upregulated or downregulated its expression in cells and subjected them to different stress stimuli. A7 

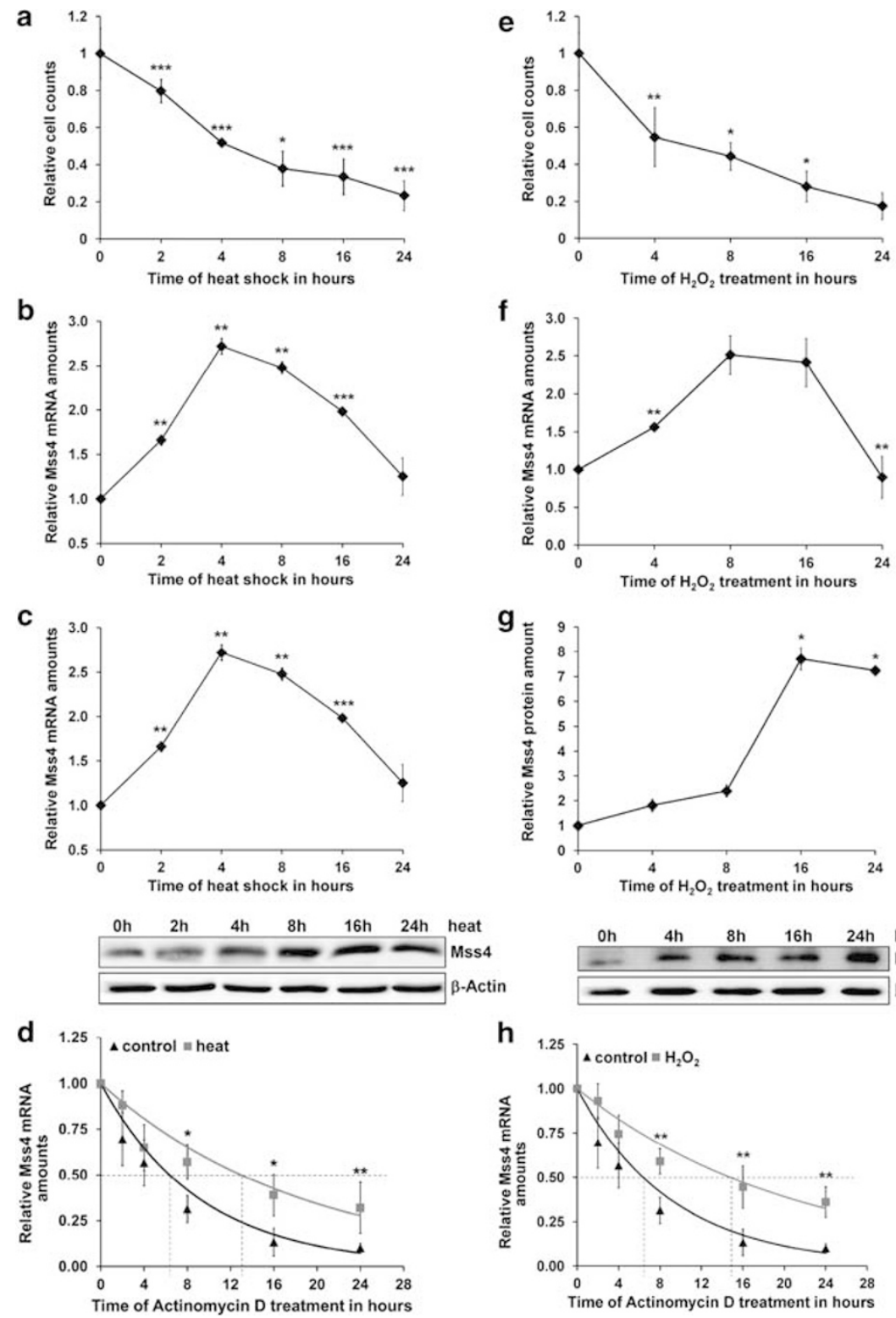

Figure 2 Endogenous Mss4 mRNA and protein response to stress stimuli. (a-c) HeLa cells were stimulated with $42^{\circ} \mathrm{C}$ for up to $24 \mathrm{~h}$ and changes in cell numbers (by counting, (a)), in Mss4 mRNA levels (by qRT-PCR, (b)) or protein levels (by western blotting, (c)) were determined. The upper image of (c) represents changes in Mss4 protein expression estimated densitometrically as the relative intensity of the Mss 4 bands of the lower image to the loading $\beta$-actin controls. Values at time point 0 were taken as unity. (d) Mss 4 mRNA decay in control or heat shocked (for $2 \mathrm{~h}$ ) A7 melanoma cells after $5 \mu \mathrm{g} / \mathrm{ml}$ actinomycin D treatment. (e-h) Changes in cell number, Mss $4 \mathrm{mRNA}$ and protein levels as well as Mss4 mRNA decay were determined as in (a-d) but after stimulation of HeLa cells with $2 \mathrm{mM} \mathrm{H}_{2} \mathrm{O}_{2} . \mathrm{H}, \mathrm{Mss} 4 \mathrm{mRNA}$ decay in control or $\mathrm{H}_{2} \mathrm{O}_{2}$ stimulated A7 melanoma cells $(2 \mathrm{mM})$. All experiments were carried out 2-4 times. Mean \pm S.D. values from a representative experiment are shown. ${ }^{*} P<0.05 ;{ }^{*} P<0.01$ and ${ }_{\star \star *} P<0.001$ relative to unstimulated cells, $t$-test

melanoma cells instead of HeLa cells were used for these experiments because we couldn't succeed in stable overexpression or downregulation of Mss4 in HeLa cells. Transduction of a myc-tagged human Mss4 by retroviral approach ensured a constitutive overexpression of Mss4 protein. To downregulate the Mss4 expression, these cells were then transiently transfected with Mss4 specific siRNA. Preliminary experiments showed that this procedure was very efficient, as only about $10 \%$ of the endogenous Mss 4 protein was usually available $48 \mathrm{~h}$ after transfection and the amount did not change significantly during at least the next
$48 \mathrm{~h}$. Of note, the siRNA also efficiently suppressed the synthesis of the recombinant myc-tagged Mss4 protein (Figure 4a). Monitoring cell morphology as well as measuring the number of apoptotic cells by a modified Nicoletti assay ${ }^{34}$ $48 \mathrm{~h}$ after siRNA transfection showed an increase in the number of round and dead cells that was already twofold higher than in control cells, which were transfected with control RNA. The control cell population itself was hardly affected. Additional stimulation of cells with either $42^{\circ} \mathrm{C}$ or $5 \mathrm{mM}$ hydrogen peroxide induced, as expected, apoptosis in both cell types but noteworthy, the increase of apoptotic 

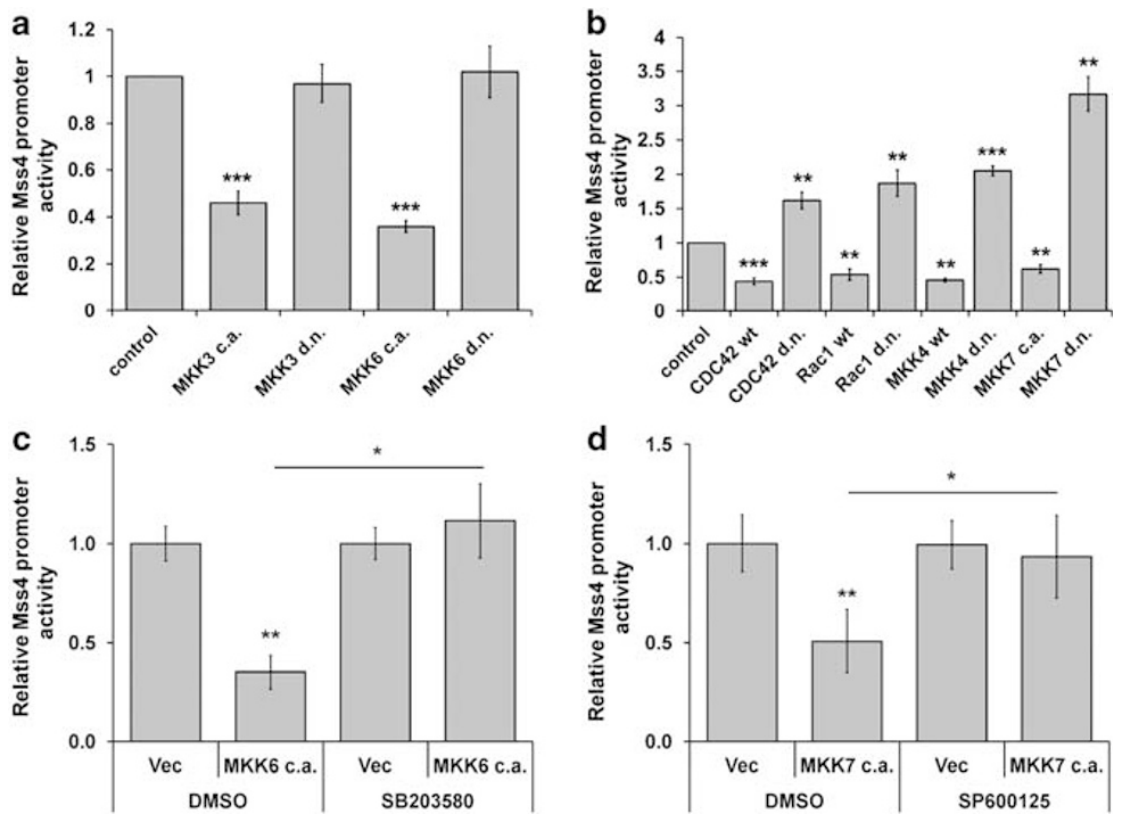

Figure 3 JNK and p38 stress MAPK pathways dowregulate Mss4 expression. A7 melanoma cells were co-transfected with reporter construct driven by the 3.6-kb Mss4 promoter fragment and different c.a. or d.n. members of the p38 (a) or JNK (b) signaling pathways. The SB203580 (c) and SP600125 inhibitors (d) were added $24 \mathrm{~h}$ after transfection with c.a. MKK6 (c) and MKK7 (d) constructs. Reporter gene activity was determined $48 \mathrm{~h}$ later. Values of control cells transfected with reporter gene construct plus empty vector were taken as unity. Mean values \pm S.D. from three repeated experiments are shown. ${ }^{*} P<0.05$, ${ }^{* *} P<0.01$ and ${ }^{* * *} P<0.001$ relative to vector-transfected control cells, $t$-test. The asterisks over the lines show the significance between inhibitor- and DMSO-treated cells

cells was much higher in siRNA transfected cells, in which the Mss4 protein was efficiently downregulated (Figures $4 b$ and $c$ ).

The anti-apoptotic properties of Mss4 were further confirmed by measuring the so-called Poly (ADP-ribose) Polymerase- or PARP-cleavage. PARP is a target of Caspase- 3 and its cleavage, thus, resembles the ongoing apoptotic process. As data of Figure 4d indicate, A7 melanoma cells show an up to twofold lower PARP-cleavage after hydrogen peroxide stimulation when they have been transiently transfected with a myc-tagged Mss4 plasmid compared with empty vector transfected cells. Together, these data apply that the amount of Mss4 protein in cells is critical for triggering cells into programmed cell death.

Interaction of Mss4 with elF3F prevents the elF3F-mediated apoptosis. To gain insight into possible molecular mechanism by which Mss4 exercise the antiapoptotic function, we screened a human placenta cDNA library for potential Mss4 binding proteins employing the yeast two-hybrid approach. The most abundant and prospect interaction partner was elF3f, the eukaryotic translation initiation factor 3 subunit $\mathrm{f}$. The $47-\mathrm{kDa}$ elF3f protein is not only a potential part of the functional core of elF3, but also possesses pro-apoptotic properties as recent studies have shown. ${ }^{23,35}$ Interaction analysis of the two proteins showed that only mutation of the F75 amino acid located on the interface of the conserved core domain of Mss4 but not deletion of the flexible non-conserved $\mathrm{N}$-terminal part or the EF-loop abrogated the association with elF3f. This holds for direct yeast two-hybrid interaction tests and for co-immunoprecipitation assays after overexpression of both proteins in mammalian cells as well (Figures $5 a$ and $b$, lanes 1-3). Further, removing of the first $\mathrm{N}$-terminal 20 amino acids, including the first $\beta$-strand of Mss4 abrogated the observed Mss4/ elF3f interaction, suggesting that maintaining of the intact protein structure is critical for this binding.

To study whether stress application influences the binding of Mss4 to elF3f, HEK293 cells were transfected with myctagged elF3f along with GST-tagged Mss4 and stimulated for 8h with $5 \mathrm{mM} \mathrm{H}_{2} \mathrm{O}_{2}$ or left untreated. The GST pull-down analysis showed that stress application strengthened the interaction between Mss4 and elF3f (Figure 5b, compare lanes 2 and 5). Of note, similar to non-stressed cells, only wt Mss4 but not the F75A mutated version was able to bind elF3f in hydrogen peroxide stimulated cells. In agreement with these data, only cells stably overexpressing wt Mss4 but not the Mss4 F75A protein were able to withstand a long-lasting (16 h) hydrogen peroxide stress (Figure $5 \mathrm{c}$ ), suggesting that binding of Mss4 to elF3f is rather critical for escaping from apoptosis. Transfection of these cells with Mss4 specific siRNA confirmed this thesis and showed that expression of an intact Mss4 protein is indeed needed for efficient protection against apoptosis (Figure $5 d$ ).

To further investigate the significance of the Mss4/elF3f interaction in context of apoptosis, we transiently transfected A7 cells with plasmids coding for Mss4, elF3f or for both and stimulated the cells $40 \mathrm{~h}$ later for additional $8 \mathrm{~h}$ with $5 \mathrm{mM}$ hydrogen peroxide and studied the cell morphology. Although overexpression of Mss4 did not have an impact on the cell morphology in non-stimulated cells, overexpression of elF3f already led to an increased number of rounded up and lysed cells. As expected, the $\mathrm{H}_{2} \mathrm{O}_{2}$ stress resulted in increased damage of vector-transfected control cells and especially of elF3f transfected cells. Of note, in contrary to elF3f, overexpression of Mss4 was not only able to protect the destructive effect of hydrogen peroxidase but also 

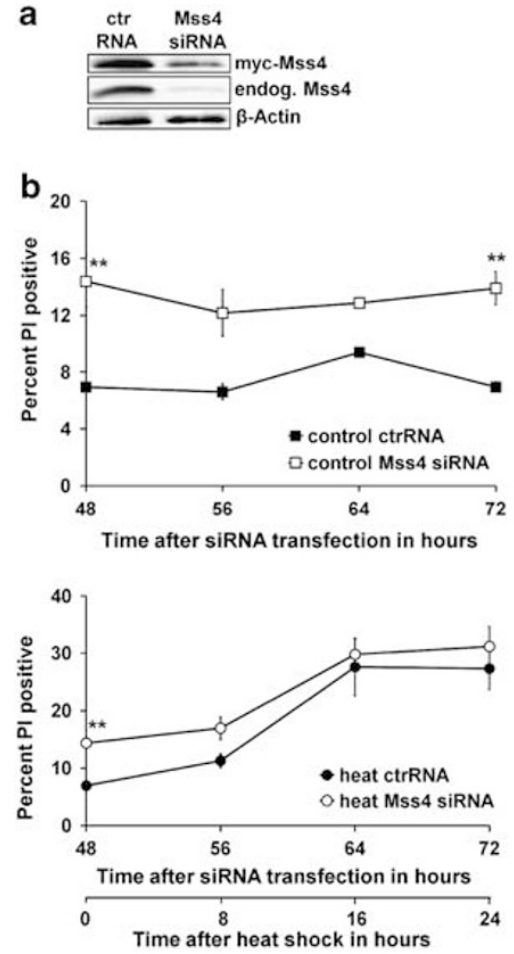
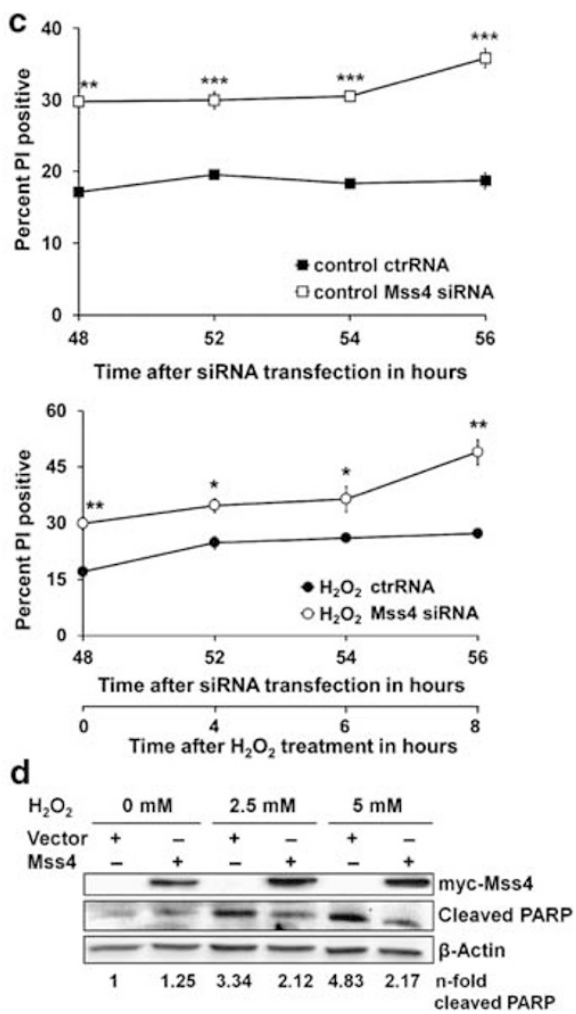

Figure 4 Mss4 downregulation induces cell apoptosis. (a) A7 melanoma cells stably overexpressing human myc-tagged Mss4 were transfected with control or Mss4 specific siRNA for $48 \mathrm{~h}$ and the knockdown efficiency of endogenous and recombinant Mss 4 protein was evaluated by Western blotting. Immunoblot for $\beta$-actin served as loading control. (b and c) A7 melanoma cells stably overexpressing human myc-tagged Mss4 were transfected with control or Mss4 specific siRNA. Forty-eight hours later the cells were either stimulated with $42^{\circ} \mathrm{C}\left(\right.$ b) or $5 \mathrm{mM} \mathrm{H}_{2} \mathrm{O}_{2}$ (c) for times indicated, stained with $\mathrm{Pl}$ and the number of apoptotic cells was determined by flow cytometry. Mean values \pm S.D. from 2-3 repeated experiments are shown. (d) A7 melanoma cells were transiently transfected with myc-tagged Mss4 or empty vector for 40h. Then the cells were stressed with 2.5 or $5 \mathrm{mM} \mathrm{H}_{2} \mathrm{O}_{2}$ for $8 \mathrm{~h}$, lysed with RIPA buffer and the expression of Mss 4 protein, as well as cleaved PARP was evaluated by western blotting. The $\beta$-actin immunoblot served as loading control. The $n$-fold PARP cleavage was estimated densitometrically as the relative intensity of cleaved PARP bands to the loading controls. Values of vector transfected and non-stressed cells were taken as unity. All experiments were carried out at least three times. ${ }^{*} P<0.05,{ }^{* *} P<0.01$ and ${ }^{* \star \star} P<0.001$ relative to ctrRNA transfected unstressed cells, $t$-test

significantly reduced the cell damage mediated by overexpressed elF3f protein in control and $\mathrm{H}_{2} \mathrm{O}_{2}$ stimulated cells as well (Figure 5 e).

Finally, to substantiate the role of Mss4/elF3f interaction in protection of stress-induced apoptosis, we transiently transfected divergent A7 melanoma cell lines that constitutively expressed different levels of either endogenous, recombinant wt or F75A mutated Mss4 proteins (Figure 5f) with a plasmid coding for human elF3f and subsequently subjected them to hydrogen peroxide stress for $8 \mathrm{~h}$. Cells transduced with empty vector alone served as controls. The constitutive overexpression of recombinant Mss4 variants was achieved by retroviral infection and the constitutive knockdown of endogenous Mss4 protein by lentiviral transduction of Mss4 specific shRNA (Figure $5 f$ ). The degree of apoptosis was measured by the modified Nicoletti assay after staining of cells with propidium iodide (PI) (Figure $5 \mathrm{~g}$ ). As expected, only overexpression of wt Mss4 was able to lessen the impact of the $\mathrm{H}_{2} \mathrm{O}_{2}$, the elF3f and their combined apoptosis as well. Mss4-knockdown had, similar to overexpression of Mss4 F75A no protective effect, but yet promoted the apoptotic cell death.

The pro-apoptotic action of eF3F was reported to be based on its ability to suppress protein translation being phosphorylated by CDK11p46. ${ }^{23,35,36}$ To study whether Mss4 is capable to abolish this specific property of elF3f protein, A7 melanoma cells were transfected with pCS2 + MT empty vector, pCS2 + MT-Mss4 and pCS2 + MT-elF3f or both plasmids together in addition to $\mathrm{PRL}-\mathrm{CMV}$ vector in which the luciferase reporter gene is controlled by the CMV promoter. Luciferase activity measured $24 \mathrm{~h}$ later showed that elF3f efficiently downregulated luciferase synthesis, whereas Mss4 alone had no effect. However, when Mss4 was co-expressed with elF3f, it abrogated the suppressive function of elF3f (Figure 6a). Quantification of luciferase mRNA by qRT-PCR demonstrated that translation of luciferase gene was not influenced by overexpression of Mss4 (Figures 6b-d), indicating that Mss4 is indeed able to abolish the elF3f-mediated inhibition of translation.

\section{Discussion}

We show here that expression of Mss4 is strongly regulated by stress stimuli at both transcription and posttranscriptional levels. Although Mss 4 is upregulated at early stages of stress stimulation, it drops down at later stages. We further show that high expression levels of Mss4 protein are beneficial for cells, as they protect cells from stress-induced apoptosis. Finally, we illustrate that anti-apoptotic properties of Mss4 are based 


\begin{tabular}{|c|c|c|}
\hline BD & $\begin{array}{l}\text { Empty } \\
\text { vector }\end{array}$ & elF3f \\
\hline Empty vector & - & - \\
\hline Mss4-wt (aa 1-123) & - & +++ \\
\hline Mss4-del1 (aa 11-123) & - & +++ \\
\hline Mss4-del2 (aa 20-123) & - & - \\
\hline Mss4-F75A & - & - \\
\hline $\begin{array}{c}\text { Mss4- } \Delta E F-\text { loop } \\
(\Delta 49-55)\end{array}$ & - & +++ \\
\hline
\end{tabular}

b

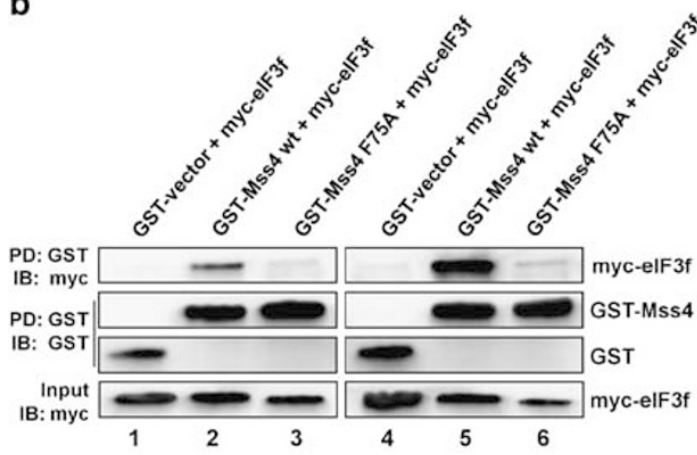

C

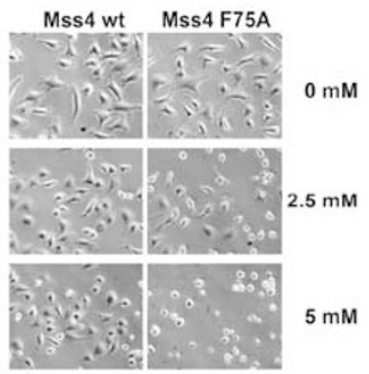

d
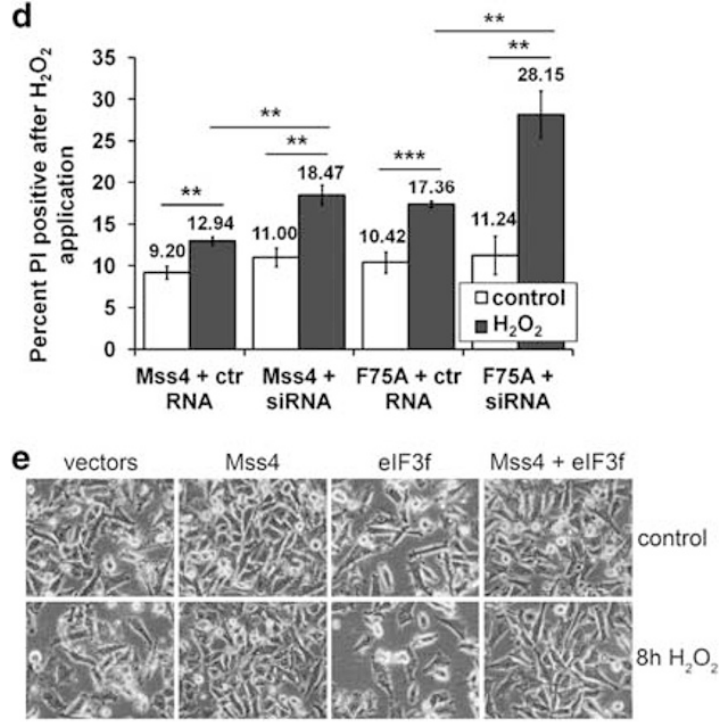

f

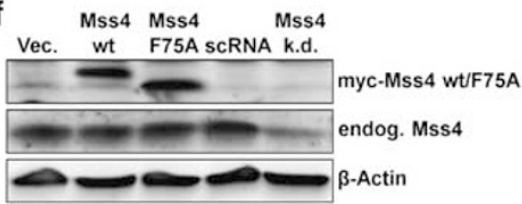

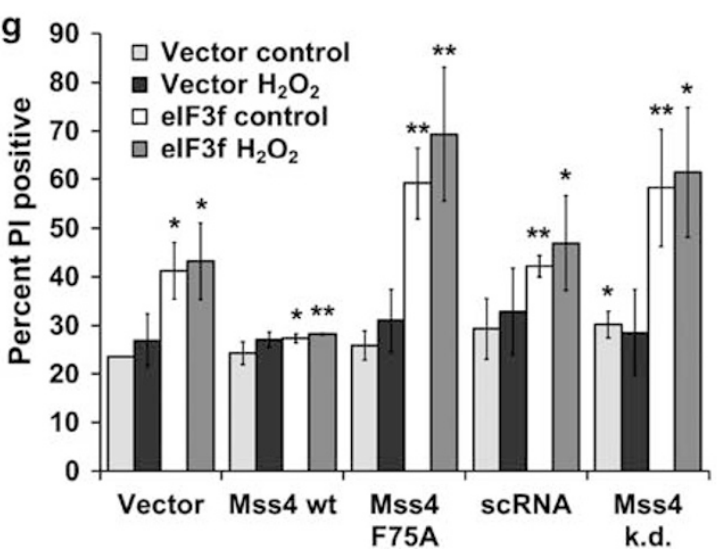

Figure 5 Interaction of Mss4 with elF3F prevents the elF3F-mediated apoptosis. (a) To measure the interaction between different Mss4 mutants and elF3f in a direct yeast-binding assay, yeast $Y 190$ cells were transformed with GAL4 DNA-binding domain (BD) and GAL-4 activation domain (AD) chimeric constructs as indicated and a $\beta$-Gal filter assay was performed as described in Materials and Methods. (b) HEK 293 cells were transiently transfected with DNA constructs as indicated, left untreated (lanes 1-3) or stimulated with $5 \mathrm{mM} \mathrm{H}_{2} \mathrm{O}_{2}$ for $8 \mathrm{~h}$ (lanes 4-6) and lysed with TLB. The presence of myc-tagged elF3f protein in GST-Mss4 wt or GST-Mss4 F75A pull downs (PD) were detected by immunoblotting (IB) with myc antibody (top blot). To ascertain equal amounts of precipitated Mss4 or GST proteins, the blot was redeveloped with antibodies against GST. The blot on the bottom shows the expression in transfected cells of elF3f protein. $10 \mu \mathrm{g}$ of total cell lysates were loaded. (c) A7 melanoma cell stably overexpressing Mss4 wt or Mss4 F75A were stressed with 2.5 or $5 \mathrm{mM} \mathrm{H}_{2} \mathrm{O}_{2}$ for $16 \mathrm{~h}$ and phase-contrast pictures were taken to document morphological changes. (d) A7 melanoma cell stably overexpressing Mss4 wt or Mss4 F75A were transfected with ctr or Mss4 specific siRNA and stimulated 48h later with 5 mM $\mathrm{H}_{2} \mathrm{O}_{2}$ for additional $8 \mathrm{~h}$. Numbers over the columns represent the amount of apoptotic cells that were determined by flow cytometry after staining of cells with PI. Mean values \pm S.D. from three repeated experiments are shown. ${ }^{\star *} P<0.01$ and ${ }^{* \star *} P<0.001$ relative to vector-transfected control cells, $t$-test. (e) A7 melanoma cells were transiently transfected with GST-tagged Mss4 and myc-tagged elF3f, either separately or together and stressed with $5 \mathrm{mM} \mathrm{H}_{2} \mathrm{O}_{2}$ for 8 h. Phase-contrast images were taken to document morphological changes in stressed (lower panels) compared with control (upper panels) cells. (f) Western blot analysis of cells examined in (g) demonstrating different expression levels of endogenous and recombinant Mss 4 proteins. $\beta$-actin immunoblot served as loading control. (g) To stably overexpress the Mss4 protein, A7 melanoma cell were retrovirally transduced with myc-tagged wt or F75A mutated Mss4 variants. Vector-transduced cells served as control. To stably downregulate the endogenous Mss4, A7 cells were infected with lentiviruses containing either scrambled or Mss4 specific shRNA. The five A7 cell lines with different amounts of endogenous or recombinant Mss 4 proteins were transfected with myc-tagged elF3f or empty vector and $40 \mathrm{~h}$ later stimulated with $5 \mathrm{mM} \mathrm{H}_{2} \mathrm{O}_{2}$ for further $8 \mathrm{~h}$. The amount of apoptotic cells was documented by flow cytometry after PI staining. Mean values \pm S.D. from two repeated experiments are shown. ${ }^{*} P<0.05$, ${ }^{*} P<0.01$ and ${ }^{* \star *} P<0.001$ relative to control vector-transfected cells, $t$-test

on its tight binding to elF3f protein, which results in inhibition of pro-apoptotic activity of the latter.

Exposure of cells to high temperature or other stress stimuli lead to increased expression of heat shock proteins that have a clear role, to protect cellular proteins from aggregation and misfolding. When stress is extended and reaches particular thresholds the protection usually fails and cells start the programmed cell death. The upregulation of heat shock 

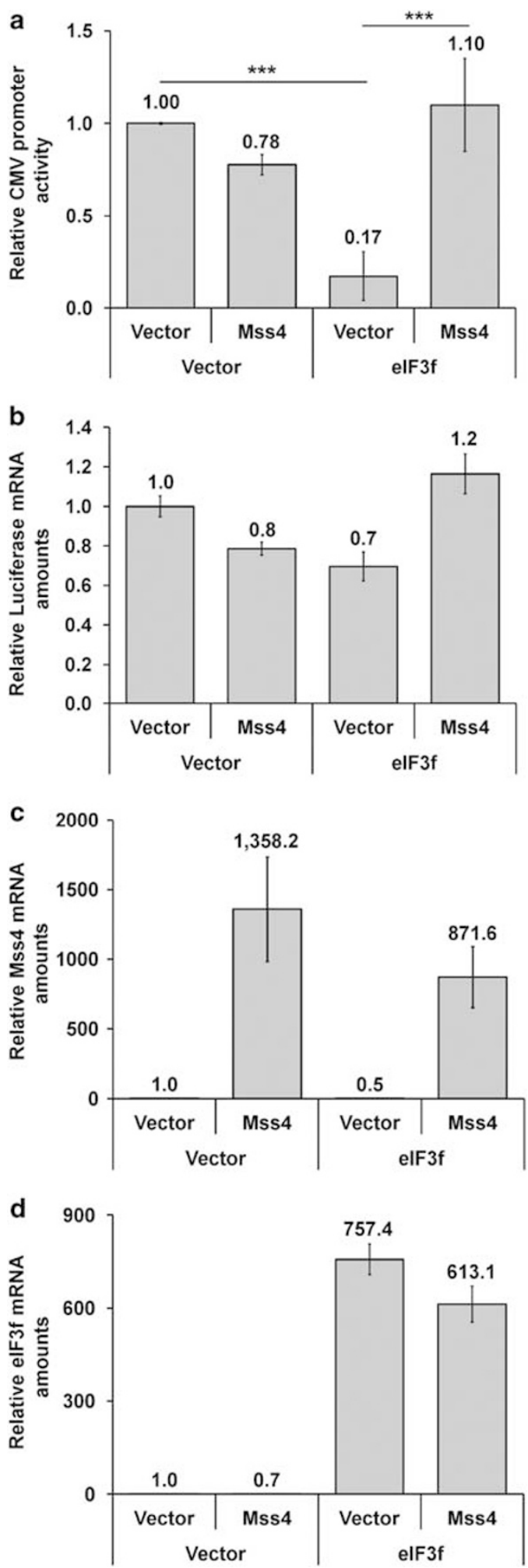

Figure 6 Expression of Mss4 abrogates the elF3f-mediated inhibition of translation. A7 melanoma cells were transfected with $\mathrm{PRL}-\mathrm{CMV}$ vector along with either empty pCS2 + MT vector or pCS2 + MT-Mss4, pCS2 + MT-elF3f or both plasmids, and $24 \mathrm{~h}$ later cell lysates were tested for luciferase activity (a), amounts of mRNA for luciferase (b), Mss4 (c) and elF3f (d). Mean values \pm S.D. from two repeated experiments are shown. ${ }^{* \star *} P<0.001$ relative to vector-transfected cells, t-test proteins on heat stimulation is usually temporary ${ }^{30}$ and is achieved not only through enhanced HSF transcription rate but also via stabilization of the mRNA. ${ }^{31}$ The half-life of their mRNA is increased in order to ensure a boost of protein to do their protective job. Mss4 protein is not described as a heat shock protein so far, but in this study we were able to demonstrate that Mss 4 shows just these attributes. Its striking structural similarity to translationally controlled tumorassociated proteins ${ }^{13}$ already suggested this. Indeed, after application of $42{ }^{\circ} \mathrm{C}$ for a longer time or hydrogen peroxide stimulation, Mss4 was transiently upregulated at both mRNA and protein levels and half-life of its mRNA was prolonged compared with unstressed cells. Furthermore, similar to heat shock proteins, the amount of Mss4 dropped down with ongoing stress accomplishing the abolishing of cell resistance to stress and triggering them into the programmed cell death. Finally, the promoter sequences of Mss4 contains the characteristic 14-bp-long pelham motif that is common to the vast majority of heat shock protein gene promoters. ${ }^{37}$ In terms of these data, Mss 4 can be viewed as a novel heat shock protein. Also, its transcriptional regulation is controlled by the p38 and JNK MAPK stress signaling cascades, a feature common to many heat shock proteins. ${ }^{38,39}$

Although elF3f is known as a subunit of the core translation initiation factor elF3 with a negative impact on translation, it was also shown to have pro-apoptotic activities. ${ }^{23,35,36}$ Overexpression of elF3f facilitated apoptosis, whereas its downregulation or genetical loss had the opposite effect. ${ }^{23}$ Furthermore, during apoptosis elF3f has been shown to be bound and phosphorylated by CDK11p46 kinase. The CDK11p46 is the enzymatically active isoform of CDK11p110 which in turn is cleaved by caspase 3 under apoptotic conditions. The phosphorylated elF3f then increasingly associates with the elF3 protein complex leading to inhibition of translation and to increased apoptosis. ${ }^{35}$ We showed here that the Mss4 protein amount not only increases during first stages of stress stimulation, but that Mss4 also efficiently binds the elF3f protein. The association of Mss4 with elF3f suggests that Mss4 is probably involved in regulation of protein translation. Moreover, enhanced expression of Mss4 in A7 melanoma cells neutralized the translation inhibitory effect of elF3f, implying that association of elF3f with Mss 4 is of importance in protection of cells from apoptosis and that the anti-apoptotic properties of Mss4 are based on prevention of translation inhibition by elF3f. In contrast to Mss4, the expression of elF3f is not changed during apoptosis of melanoma cells (Supplementary Figure 3 and Shi et $a l^{35}$ ). Of note, only overexpression of wt Mss 4 protein but not the F75A mutant that cannot bind to elF3f was able to inhibit the elF3f-mediated apoptosis. On the basis of these results and the already published data, we hypothesize that Mss4 binds elF3 $f$ avoiding its interaction with and phosphorylation by CDK11p46 (Figure 7). This prevents the incorporation of elF3F into the functional elF3 protein complex allowing protein translational and inhibiting apoptosis. In other words, at early stages of heat shock or other stress stimulation increasing amounts of Mss4 protein efficiently bind the elF3f preventing its interaction with CDK11p46. When the number of Mss 4 molecules in cells dropped down owing to ongoing stress, the CDK11p46 binds now and phosphorylates the 

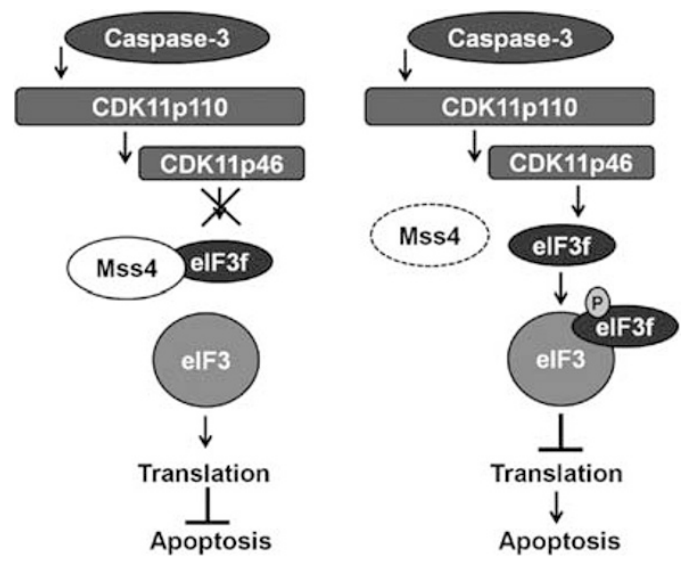

Figure 7 Proposed scheme of elF3f and Mss4 interaction in context of apoptosis. In case of regular conditions or low stress amounts Mss4 is tightly bound to elF3f, inhibiting its phosphorylation and subsequent association with elF3 protein complex and pro-apoptotic functions. (left picture). If a certain threshold of stress is crossed, Mss4 is downregulated, leading to a release of elF3f, which can now be phosphorylated by the caspase-activated CDK11p46 kinase, incorporated into the elF3 protein compound, which in turn results in inhibition of translation and induction of apoptosis (right picture)

released elF3f resulting in inhibition of translation and initiation of apoptosis.

\section{Materials and Methods}

DNA constructs and yeast two-hybrid screen. For the reporter gene assays the putative complete Mss4 (alsp known as Rabif; accession no. NM_002862.2) promoter sequence and the 1.0-kb large atg-proximal sequence only were cloned into the pGL2-luc vector (pGL2-Mss4-luc), correct in frame cloning was verified by DNA sequencing. For evaluation of transfection efficiency a CMV-driven B-galactosidase construct was used (Galacto-LightPlus System, Applied Biosystems, Foster City, CA, USA). The expression constructs for pFA2: cJun; pFA2:Elk1; pFA:cFos; kRSPA:MKK6 c.a (T658E/S670E); kRSPA:MKK6 d.n (K82A); kRSPA:MKK3 c.a (S189E/T211E); kRSPA:MKK3 d.n. (S189A/T211A); pRK5:CDC42 wt and d.n. (N17); pRK5:Rac1 wt and d.n.(N17); pEBG:MKK4 wt and d.n.(K129R) and pCS3 + MT:MKK7 c.a. (S271E, T275E,S277E) and also pCS3 + MT:MKK7 d.n. (S271A, T275A,S277A) were published elsewhere. ${ }^{40}$ The expression of appropriate proteins was tested in preliminary western blot analysis (data not shown).

The pCS2 + MT: HSF1 was produced by cloning the human HSF1 sequence (accession no. NM_005526.2) in frame behind the myc-tag using the following primers: fwd 5'-ATAGAATTCAATGGATCTGCCCGTGGGCCCC-3' and rev 5'-ACACTCGAGCTAGGAGACAGTGGGGTCCTTGG-3' from human HeLa cell cDNA as template. For the transient expression of myc-tagged Mss4 and elF3 (accession no. NM_003754.2) the respective human sequences were cloned into pCS2 + MT vector. The pEBG: Mss4 wt and F75A constructs were described before. ${ }^{10}$ For stable expression of Mss 4 wt and F75A mutant in A7 melanoma cells, the myc-tagged human Mss4 wt and F75A were removed from the pCS2 + MT plasmids and recloned into the pBabe-puro vector.

For the yeast two-hybrid screen a cDNA fragment coding for full-length human Mss4 (accession no. NM_002871) was inserted into the DNA-binding domain vector pAS2-1 and used as bait for screening a human placenta cDNA library cloned into pACT2 yeast two-hybrid vector (MATCHMAKER, Clontech, Palo Alto, CA, USA). The yeast two-hybrid screen for proteins binding to Mss4 was performed as described in. ${ }^{6}$ Mutants of Mss4, Mss4-del1 (aa 13-123); Mss4-del2 (aa 20-123); Mss4-EF loop (aa 49-55 were deleted) and Mss4-F75A (F at position 75 was exchanged for A), cloned into pAS2-1 vector were derived by extrasize-overlapping $\mathrm{PCR}$ procedure with appropriate primers and were described in. ${ }^{10}$

Cell culture and stimulations. Human HeLa cervix carcinoma cells were maintained in DMEM and human A7 melanoma cells in MEM supplemented with $10 \%$ FCS at $37^{\circ} \mathrm{C}$ and $5 \% \mathrm{CO}_{2}$. Cell stimulations were carried out under regular temperature and pressure conditions except for heat shock treatments, which have been conducted at 42 or $43^{\circ} \mathrm{C}$. Celastrol (Biomol, Hamburg, Germany) was used in concentrations of 6 and $10 \mu \mathrm{M}$ with DMSO as solvent control. For reporter gene analysis HeLa cells were stimulated for $5 \mathrm{~h}$ with: $10 \mathrm{ng} / \mathrm{ml}$ PDGF, $50 \mathrm{ng} / \mathrm{ml}$ EGF, $10 \% \mathrm{FCS}, 10 \mu \mathrm{g} / \mathrm{ml}$ anisomycin, $5 \mathrm{ng} / \mathrm{ml} \mathrm{TNF} \alpha$, $5 \mathrm{mM}$ hydrogen peroxide or $600 \mathrm{mM}$ sorbitol. The inhibition of p38- and JNK-stress cascades was accomplished by treatment with $20 \mu \mathrm{M}$ SB203580

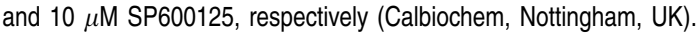

Half-life time estimation for Mss4 mRNA. For these kind of assay A7 melanoma cells were chosen because they express more endogenous Mss4 than HeLa cells. A7 cells were cultivated under regular conditions to confluency of 50-60\%. The MEM with $10 \%$ FCS was exchanged for complete medium containing $5 \mu \mathrm{g} / \mathrm{ml}$ actinomycin $\mathrm{D}$ for time periods up to $24 \mathrm{~h}$. Additionally, to study the half-life time of Mss 4 mRNA in stressed cells, the A7 cells were treated for $24 \mathrm{~h}$ with $5 \mu \mathrm{g} / \mathrm{ml}$ of actinomycin D. A $43^{\circ} \mathrm{C}$ heat shock was performed $2 \mathrm{~h}$ ahead of the actinomycin $D$ treatment, whereas the hydrogen peroxide stimulation $(5 \mathrm{mM})$ in parallel to the transcription inhibition. At the chosen time points lysates were taken in order to isolate the RNA. Subsequently the cDNA synthesis and qRT-PCR were performed. The acquired Mss4 mRNA levels were calculated relative to the unstimulated controls.

Reporter gene assay. Transfection of HeLa cells was achieved with PEI (polyethylenimine). A7 cells were transfected with FuGENE-6 (Roche, Penzberg, Germany) according to the manufacturer's instructions. The reporter plasmids pGL2-Mss4-luc (500 ng) and pCMV- $\beta$ Gal (100 ng) were co-transfected with 500ng of expression vectors for transcription factors, MKKs, or other constructs of the JNK and p38-pathway. The total plasmid DNA per dish was kept constant by adding the appropriate amount of empty expression vector. Each transfection was carried out in triplicate. Luciferase activities were measured $48 \mathrm{~h}$ after transfection using the Luciferase Assay System (Promega, Madison, WI, USA) and were normalized to $-\beta$ Galactosidase activity.

Western blotting and pull down binding assays. For western blottings cells were washed twice with PBS and lysed in RIPA supplemented with $1 \mathrm{mM}$ sodium vanadate, $200 \mu \mathrm{M}$ pefablock, $5 \mu \mathrm{g} / \mathrm{ml}$ leupeptin, and $5 \mu \mathrm{g} / \mathrm{ml}$ aprotinin for $10 \mathrm{~min}$ on ice. The lysates were cleared by centrifugation at $10000 \mathrm{~g}$ for $10 \mathrm{~min}$ at $4^{\circ} \mathrm{C}$. Supernatants were resolved by $10,12.5$ or $15 \%$ SDS-PAGE, and, after electroblotting onto a nitrocellulose membrane, proteins were detected with appropriate antibodies using the ECL detection system (Bio-Rad Inc., Munich, Germany). The antibodies used were: affinity purified rabbit polyclonal anti-Mss4, rabbit polyclonal HSF1 (Cell Signaling, Frankfurt, Germany); mouse monoclonal anti-beta-Actin (Sigma, Hamburg, Germany), rabbit polyclonal anti-cleaved PARP (Asp214) (Cell Signaling); mouse monoclonal anti-myc (9E10); mAb anti-GST (G3E7); rabbit polyclonal anti-phospho-MAPKAPK-2 (Cell Signaling); mouse monoclonal anti-phospho-JNK (Becton Dickinson, Heidelberg, Germany). All western blotting experiments were repeated 2 to 4 times.

For GST pull-down analysis $2 \times 10^{5} \mathrm{HEK} 293$ cells were plated on six-well dishes $48 \mathrm{~h}$ before transfection, which was performed with PEI. $1 \mu \mathrm{g}$ of each $\mathrm{CDNA}$ plasmid was used per transfection, and the total amount $(2 \mu \mathrm{g} /$ well) was equalized if necessary with appropriate empty expression vectors. Forty hours post transfection cells were washed twice with PBS and lysed in a Triton lysis buffer (TLB), that contained $0.5 \%$ Ttriton-X100, $25 \mathrm{mM}$ tris/ $\mathrm{HCl} \mathrm{pH} 7.5$ and $137 \mathrm{mM} \mathrm{NaCl}$, supplemented with $1 \mathrm{mM}$ sodium vanadate, $200 \mu \mathrm{M}$ pefablock, $5 \mu \mathrm{g} / \mathrm{ml}$ leupeptin, and $5 \mu \mathrm{g} / \mathrm{ml}$ aprotinin. Two hundred micrograms of total TLB cell lysates were rotated for $2 \mathrm{~h}$ at $4{ }^{\circ} \mathrm{C}$ with glutathione-sepharose beads. The beads were subsequently washed three times with TLB, resuspended in Laemmli loading buffer and heat-denatured. To reduce the nonspecific binding of proteins to sepharose beads, the latter were blocked with $1 \%$ BSA in TLB before incubation with cell lysates. Samples were resolved by $12.5 \%$ SDS-PAGE followed by electroblotting onto nitrocellulose membrane. The detection of co-precipitated proteins was performed with mouse-anti-myc (clone 9E10) and mouse-anti-GST (clone G3E7) antibodies.

mRNA isolation, cDNA synthesis and qRT-PCR. Cell lysates of accordingly stimulated cells were taken and mRNA was isolated with RNeasy Minikit (Qiagen, Hilden, Germany). cDNA synthesis was performed with Revert Aid H Minus reverse transcriptase (Fermentas, St. Leon-Rot, Germany) according to the protocol of the manufacturer. Quantitative real time polymerase chain reactions were performed with a Roche Light Cycler 480 II. RT-PCR primers were: 
human GAPDH fwd 5'-GCATCCTGGGCTACACTGAG-3', rev 5'-TGCTGTAGCCA AATTCGTTG-3'; human Mss4 fwd 5'-CTTTTCCTTCCCTCCATGAGAA-3', rev 5'-AGACCAGAAACTTGATGTTGCCCA-3', human elF3f fwd: $5^{\prime}$-TGACAGTGA AATACGCGTAC-3', rev $5^{\prime}$-GTCACTTGAGAGTCCAATCAC-3', luciferase fwd: 5'- CAACTGCATAAGGCTATGAAGAGA-3', rev 5'-ATTTGTATTCAGCCCATATC GTTT-3'.

Quantification of apoptosis. HeLa and A7 cells were treated with either heat or hydrogen peroxide for the desired time periods, the supernatants were collected, the cells detached with $5 \mathrm{mM}$ EDTA in PBS at room temperature. The consolidated cells and supernatants were centrifuged at 5000 r.p.m. for 5 minutes, the pellets washed once with PBS and then resuspended in $70 \%$ ethanol and fixed overnight at $-20^{\circ} \mathrm{C}$. Before staining with $\mathrm{Pl}$, the cells were treated with $250 \mu \mathrm{g} / \mathrm{ml}$ PureLink RNase A (Invitrogen, Karlsruhe, Germany) for 30 minutes at $37^{\circ} \mathrm{C}$. The PI staining $(10 \mu \mathrm{g} / \mathrm{ml})$ was done for 30 minutes at $37^{\circ} \mathrm{C}$. The amount of apoptotic cells was evaluated by flow cytometry (FACSCalibur, BectonDickinson, Heidelberg, Germany) as described previously.

Direct yeast two-hybrid interaction assays. The yeast strain Y190 was cotransformed with the pAS2-1 plasmid containing the GAL4-BD fused with appropriate cDNAs as bait and with pACT2 plasmids containing CDNAs fused to GAL4-AD as prey. Transformants were grown on SD medium lacking leucine, tryptophan and histidine in the presence of $25 \mathrm{mM}$ 3-amino-1,2,4-triazole. On day 6 the colonies were tested for the lacZ reporter gene activity in a $\beta$-Gal filter assay. The interaction was scored as negative $(-)$ when no blue colonies were visible after $8 \mathrm{~h}$, and scored as: weak $(+)$, intermediate $(++)$, or strong $(+++)$ when blue colonies became visible after $8 \mathrm{~h}, 4 \mathrm{~h}$ or $1 \mathrm{~h}$, respectively.

\section{Conflict of Interest}

The authors declare no conflict of interest.

Acknowledgements. This work was supported by the Wilhelm SanderStiftung Grant 2007.029.1 and SFB492A17 to VW and by SFB/Transregio 23 (TPA9) and DLC (SWS SCHN 474/4-1) to SWS.

1. Schlesinger MJ. Heat shock proteins: the search for functions. J Cell Biol 1986; 103: 321-325.

2. Kultz D. Molecular and evolutionary basis of the cellular stress response. Annu Rev Physiol 2005; 67: 225-257.

3. Lindquist S, Craig EA. The heat-shock proteins. Annu Rev Genet 1988; 22: 631-677.

4. Burton JL, Burns ME, Gatti E, Augustine GJ, De Camilli P. Specific interactions of Mss4 with members of the Rab GTPase subfamily. EMBO J 1994; 13: 5547-5558.

5. Wixler V, Laplantine E, Geerts D, Sonnenberg A, Petersohn D, Eckes B et al. Identification of novel interaction partners for the conserved membrane proximal region of alpha-integrin cytoplasmic domains. FEBS Lett 1999; 445: 351-355.

6. Wixler V, Wixler L, Altenfeld A, Ludwig S, Goody RS, Itzen A. Identification and characterisation of novel Mss4-binding Rab GTPases. Biol Chem 2011; 392: 239-248.

7. Burton J, Roberts D, Montaldi M, Novick P, De Camilli P. A mammalian guaninenucleotide-releasing protein enhances function of yeast secretory protein Sec4. Nature 1993; 361: 464-467.

8. Itzen A, Pylypenko O, Goody RS, Alexandrov K, Rak A. Nucleotide exchange via local protein unfolding-structure of Rab8 in complex with MSS4. EMBO J 2006; 25: 1445-1455.

9. Nuoffer C, Wu SK, Dascher C, Balch WE. Mss4 does not function as an exchange factor for Rab in endoplasmic reticulum to Golgi transport. Mol Biol Cell 1997; 8: 1305-1316.

10. Knoblauch A, Will C, Goncharenko G, Ludwig S, Wixler V. The binding of Mss4 to alphaintegrin subunits regulates matrix metalloproteinase activation and fibronectin remodeling FASEB J 2007; 21: 497-510.

11. $\mathrm{Yu} \mathrm{H}, \mathrm{Schreiber} \mathrm{SL}$. Structure of guanine-nucleotide-exchange factor human Mss4 and identification of its Rab-interacting surface. Nature 1995; 376: 788-791.

12. Zhu Z, Delprato A, Merithew E, Lambright DG. Determinants of the broad recognition of exocytic Rab GTPases by Mss4. Biochemistry 2001; 40: 15699-15706.

13. Thaw P, Baxter NJ, Hounslow AM, Price C, Waltho JP, Craven CJ. Structure of TCTP reveals unexpected relationship with guanine nucleotide-free chaperones. Nat Struct Biol 2001; 8: 701-704.

14. Gnanasekar M, Dakshinamoorthy G, Ramaswamy K. Translationally controlled tumor protein is a novel heat shock protein with chaperone-like activity. Biochem Biophys Res Commun 2009; 386: 333-337.

15. Kashiwakura JC, Ando T, Matsumoto K, Kimura M, Kitaura J, Matho MH et al. Histaminereleasing factor has a proinflammatory role in mouse models of asthma and allergy. $J$ Clin Invest 2012; 122: 218-228.

16. Hinnebusch AG. elF3: a versatile scaffold for translation initiation complexes. Trends Biochem Sci 2006; 31: 553-562.

17. Asano K, Kinzy TG, Merrick WC, Hershey JW. Conservation and diversity of eukaryotic translation initiation factor elF3. J Biol Chem 1997; 272: 1101-1109.

18. Asano K, Merrick WC, Hershey JW. The translation initiation factor elF3-p48 subunit is encoded by int- 6 , a site of frequent integration by the mouse mammary tumor virus genome. J Biol Chem 1997; 272: 23477-23480.

19. Zhou C, Arslan F, Wee S, Krishnan S, Ivanov AR, Oliva A et al. $\mathrm{PCl}$ proteins elF3e and elF3m define distinct translation initiation factor 3 complexes. BMC Bio/ 2005; $3: 14$

20. Aravind L, Ponting CP. Homologues of $26 \mathrm{~S}$ proteasome subunits are regulators of transcription and translation. Protein Sci 1998; 7: 1250-1254.

21. Doldan A, Chandramouli A, Shanas R, Bhattacharyya A, Cunningham JT, Nelson MA et al. Loss of the eukaryotic initiation factor $3 f$ in pancreatic cancer. Mol Carcinog 2008; 47: 235-244.

22. Doldan A, Chandramouli A, Shanas R, Bhattacharyya A, Leong SP, Nelson MA et al. Loss of the eukaryotic initiation factor $3 f$ in melanoma. Mol Carcinog 2008; 47: 806-813.

23. Shi J, Kahle A, Hershey JW, Honchak BM, Warneke JA, Leong SP et al. Decreased expression of eukaryotic initiation factor $3 f$ deregulates translation and apoptosis in tumor cells. Oncogene 2006; 25: 4923-4936.

24. Tang D, Gururajan R, Kidd VJ. Phosphorylation of PITSLRE p110 isoforms accompanies their processing by caspases during Fas-mediated cell death. J Biol Chem 1998; 273: 16601-16607.

25. Chiu R, Boyle WJ, Meek J, Smeal T, Hunter T, Karin M. The c-Fos protein interacts with C-Jun/AP-1 to stimulate transcription of AP-1 responsive genes. Cell 1988; 54: 541-552.

26. Gille $\mathrm{H}$, Kortenjann M, Thomae $\mathrm{O}$, Moomaw $\mathrm{C}$, Slaughter $\mathrm{C}$, Cobb $\mathrm{MH}$ et al. ERK phosphorylation potentiates Elk-1-mediated ternary complex formation and transactivation. EMBO J 1995; 14: 951-962.

27. Rabindran SK, Giorgi G, Clos J, Wu C. Molecular cloning and expression of a human heat shock factor, HSF1. Proc Natl Acad Sci USA 1991; 88: 6906-6910.

28. Sorger PK. Heat shock factor and the heat shock response. Cell 1991; 65: 363-366.

29. Westerheide SD, Bosman JD, Mbadugha BN, Kawahara TL, Matsumoto G, Kim S et al. Celastrols as inducers of the heat shock response and cytoprotection. J Biol Chem 2004; 279: 56053-56060.

30. Subjeck JR, Sciandra JJ, Chao CF, Johnson RJ. Heat shock proteins and biological response to hyperthermia. Br J Cancer.Supplement 1982; 5: 127-131.

31. Theodorakis NG, Morimoto RI. Posttranscriptional regulation of hsp70 expression in human cells: effects of heat shock, inhibition of protein synthesis, and adenovirus infection on translation and mRNA stability. Mol Cell Biol 1987; 7: 4357-4368.

32. Clerk A, Fuller SJ, Michael A, Sugden PH. Stimulation of "stress-regulated" mitogenactivated protein kinases (stress-activated protein kinases/c-Jun N-terminal kinases and p38-mitogen-activated protein kinases) in perfused rat hearts by oxidative and other stresses. J Biol Chem 1998; 273: 7228-7234.

33. Lo YY, Wong JM, Cruz TF. Reactive oxygen species mediate cytokine activation of c-Jun NH2-terminal kinases. J Biol Chem 1996; 271: 15703-15707.

34. Ohnesorge N, Viemann D, Schmidt N, Czymai T, Spiering D, Schmolke M et al. Erk5 activation elicits a vasoprotective endothelial phenotype via induction of Kruppel-like factor 4 (KLF4). J Biol Chem 2010; 285: 26199-26210.

35. Shi J, Hershey JW, Nelson MA. Phosphorylation of the eukaryotic initiation factor $3 f$ by cyclin-dependent kinase 11 during apoptosis. FEBS Lett 2009; 583: 971-977.

36. Shi J, Feng Y, Goulet AC, Vaillancourt RR, Sachs NA, Hershey JW et al. The p34cdc2related cyclin-dependent kinase 11 interacts with the p47 subunit of eukaryotic initiation factor 3 during apoptosis. J Biol Chem 2003; 278: 5062-5071.

37. Pelham HR. A regulatory upstream promoter element in the Drosophila hsp 70 heat-shock gene. Cell 1982; 30: 517-528.

38. Benjamin IJ, McMillan DR. Stress (heat shock) proteins: molecular chaperones in cardiovascular biology and disease. Circ Res 1998; 83: 117-132.

39. Santoro MG. Heat shock factors and the control of the stress response. Biochem Pharmacol 2000; 59: 55-63.

40. Ludwig S, Hoffmeyer A, Goebeler M, Kilian K, Hafner H, Neufeld B et al. The stress inducer arsenite activates mitogen-activated protein kinases extracellular signal-regulated kinases 1 and 2 via a MAPK kinase 6/p38-dependent pathway. J Biol Chem 1998; 273: 1917-1922.

(c)

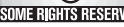

Cell Death and Disease is an open-access journal published by Nature Publishing Group. This work is licensed under the Creative Commons Attribution-NonCommercial-No Derivative Works 3.0 Unported License. To view a copy of this license, visit http://creativecommons.org/licenses/by-nc-nd/3.0/ 